Sigmar de Mello Rode

Scientific Editor

\title{
Editorial consolidation, a reality
}

n 2011, Brazilian Oral Research - BOR made great advances in the form of broader dissemination and greater International penetration, largely as a result of participation in meetings of the IADR and the Associação Brasileira de Editores Científicos (ABEC - Brazilian Association of Scientific Editors). The publication of studies involving International collaboration (nearly $25 \%$ of papers) is evidence of the advances made by the journal and a surefire way of increasing the number of citations. Furthermore, the greater number of submissions, particularly from non-Portuguese speaking countries, has led to more rigorous review of manuscripts prior to acceptance, and to a greater participation of non-Brazilian reviewers.

With the implementation of our editorial policy we now accept a wider variety of manuscript types. This leads to increased visibility of the journal, given that good review articles are associated with a higher number of citations. Today we can define a series of high-interest issues or polemic topics in advance and address these in the pages of BOR, with a view to critically systematize the current state of knowledge in a given area, with input from leading national and international scholars. In addition, the frequency of publication has increased to a bi-monthly issue, further increasing the number of articles published. Also noteworthy is the partnership forged with the Associação Brasileira de Odontologia de Promoção de Saúde (ABOPREV - Brazilian Association of Oral Health Promotion), in a joint production of a special issue.

Another important step has been the refining of control measures aimed at improving transparency and ethics, detecting and preventing incidents of plagiarism, self-plagiarism, and false co-authorship (publication of names of authors who have not contributed significantly to the study), among other undesirable practices.

Although we have been working hard to offer quality review in the shortest time frame possible, cutting down publication times further calls for improvements on two fronts: reducing the time dedicated by reviewers to assessing manuscripts, and reducing the time required by authors to revise and correct them. Bearing this in mind, we have adopted the practice of publishing articles ahead of print. This entails digital publication of individual articles immediately after approval, without the need to await compilation of the complete issue. We are also adopting, on a trial basis, the ScholarOne system of digital submission on the Scielo database. Once implemented, this system will streamline the manuscript submission and peer-review process.

And most importantly, owing to our involvement in the Scielo database, as of 2012 we shall be included in Thomson Reuters's Web of Knowledge. This is likely to greatly increase our impact factor within a short period of time. In addition, given that the coordinators of CAPES have elected BOR as a beneficiary of financial support from this funding agency, our Qualis index is also set to rise in conjunction with our level of internationalization.

BOR's Publishing Commission, Editorial Board and reviewers alike, all work on a voluntary basis, and their efforts often go unrecognized. However, as shown, we have striven to make sure that BOR is worthy of representing the Sociedade Brasileira de Pesquisa Odontológica (SBPqO - Brazilian Society of Dental Research) and consequently Brazilian dentistry as a whole. 